\section{Commentary: Delayed gratification and optimism bias: Navigating quality and quantity of life with revascularization in patients with ischemic cardiomyopathy}

\author{
Moritz C. Wyler von Ballmoos, MD, PhD, MPH, ${ }^{\mathrm{a}, \mathrm{b}}$ \\ and G. Hossein Almassi, MD ${ }^{\mathrm{c}, \mathrm{d}}$
}

Revascularization for coronary artery disease arguably is one of the most studied and scrutinized fields in medicine. Percutaneous coronary intervention (PCI) continues to provide the most significant benefit in the setting of acute coronary syndrome, where it is lifesaving. Yet, and despite advances in technology, PCI has failed to match the benefits of coronary artery bypass grafting (CABG) in terms of mortality, need for revascularization, and major adverse cardiac and cerebrovascular events (MACCEs) in stable coronary artery disease. Recent large randomized clinical trials have shown $\mathrm{CABG}$ to be superior in the long run in patients with unprotected left main disease and those with more than single-vessel disease, especially in patients with diabetes. ${ }^{1-5}$

However, patients with ischemic cardiomyopathy have been notably absent from these studies, and all trials investigating newer stent technology for that matter. In this edition of the Journal, Bianco and colleagues ${ }^{6}$ report a single-institution comparative effectiveness study of PCI and $\mathrm{CABG}$ in 2000 patients with reduced ejection fraction $<50 \%$ (mean 35\%). After propensity-score matching, they identified 324 pairs in which they compared the 2 treatment strategies. In this matched cohort, they show a significant disadvantage of PCI over CABG at 3 years of follow-

From the a Department of Cardiothoracic Surgery, DeBakey Heart \& Vascular Center, Houston, Tex; ' ${ }^{\mathrm{b}}$ Weill Cornell Medicine, New York, NY; ${ }^{\mathrm{c} D i v i s i o n}$ of Cardiothoracic Surgery, Department of Surgery, Medical College of Wisconsin, Milwaukee; and ${ }^{\mathrm{d}}$ Zablocki VA Medical Center, Milwaukee, Wis.

Disclosures: The authors reported no conflicts of interest.

The Journal policy requires editors and reviewers to disclose conflicts of interest and to decline handling or reviewing manuscripts for which they may have a conflict of interest. The editors and reviewers of this article have no conflicts of interest.

Received for publication July 13, 2020; revisions received July 13, 2020; accepted for publication July 14, 2020; available ahead of print July 18, 2020.

Address for reprints: G. Hossein Almassi, MD, Division of Cardiothoracic Surgery, Medical College of Wisconsin, 8701 Watertown Plank Rd, Milwaukee, WI 53226 (E-mail: halmassi@mcw.edu).

J Thorac Cardiovasc Surg 2021;161:1032-3

$0022-5223 / \$ 36.00$

Copyright (c) 2020 by The American Association for Thoracic Surgery

https://doi.org/10.1016/j.jtcvs.2020.07.049

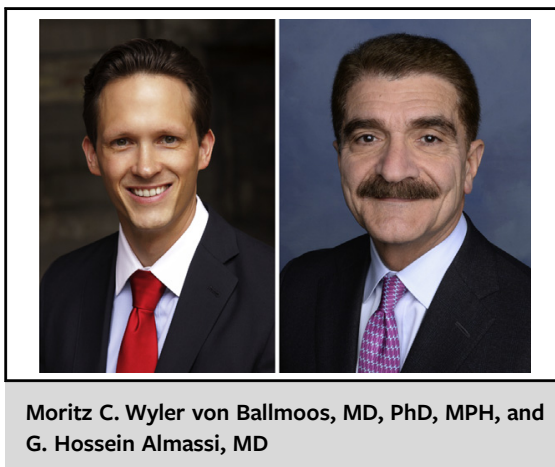

CENTRAL MESSAGE
This study corroborates findings
of large RCTS, providing further
evidence that CABG is superior
to a PCI first strategy in a rapidly
growing population of patients
with ischemic cardiomyopathy.

up for all-cause mortality ( $37.4 \%$ vs $21.3 \%$ ), $\geq 1$ hospital readmission ( $24.1 \%$ vs $12.9 \%$ ), MACCEs ( $41.4 \%$ vs $23.8 \%$ ), and repeat revascularization ( $6.5 \%$ vs $2.6 \%)$. In models adjusting for age, race, several comorbidities, and importantly, completeness of revascularization, they also show substantially better freedom from MACCEs, repeat revascularization, and survival with CABG at 1 and 5 years.

These differences between PCI and CABG are not subtle and should give clinicians pause when evaluating patients with ischemic cardiomyopathy. Furthermore, MACCEs all tend to independently increase the risk for a subsequent event of the same category; for that reason and since the authors modeled only the risk to a first event, one must assume that the true effect may be even bigger.

The study has some noteworthy limitations. While propensity-score matching has become enormously popular, its weaknesses and potential for introducing imbalance, inefficiency, model dependence, and bias are also increasingly being recognized. ${ }^{7}$ Yet, the study findings are credible and provide actionable evidence for clinical practice. The results are consistent with the mortality benefit of CABG over medical treatment alone demonstrated in the STICH (Surgical Treatment for Ischemic Heart Failure) ${ }^{8}$ and a recently published study confirming a significant benefit of CABG over PCI. ${ }^{9}$

CABG has consistently been associated with improved survival, fewer myocardial infarction events, and revascularization and, for most patients, an equivalent stroke rate over the long term, compared with PCI. The study by Bianco and 
colleagues provides valuable evidence that benefit may be accentuated in patients with ischemic cardiomyopathy. The benefits of PCI naturally prevail over gained lifetime in frail patients, a limited life expectancy, or otherwise limited goals of care. The more challenging task remains to convey the average long-term benefits of a big surgery to an otherwise functional individual to whom the actual outcome remains unknown. The human tendency to assimilate positive information and rationalize away negative information is well established and plays a vital role in these decision processes. ${ }^{10}$ The specific challenge is perhaps best met with a team of multiple specialties providers.

\section{References}

1. Stone GW, Kappetein AP, Sabik JF, Pocock SJ, Morice M-C, Puskas J, et al. Fiveyear outcomes after PCI or CABG for left main coronary disease. $N$ Engl J Med. 2019;381:1820-30.

2. Park S-J, Ahn J-M, Kim Y-H, Park D-W, Yun S-C, Lee J-Y, et al. Trial of everolimus-eluting stents or bypass surgery for coronary disease. $N$ Engl $J$ Med. 2015;372:1204-12.
3. Head SJ, Milojevic M, Daemen J, Ahn J-M, Boersma E, Christiansen EH, et al. Mortality after coronary artery bypass grafting versus percutaneous coronary intervention with stenting for coronary artery disease: a pooled analysis of individual patient data. Lancet. 2018;391:939-48.

4. Farkouh ME, Domanski M, Sleeper LA, Siami FS, Dangas G, Mack M, et al. Strategies for multivessel revascularization in patients with diabetes. $N$ Engl $J$ Med. 2012;367:2375-84.

5. Mäkikallio T, Holm NR, Lindsay M, Spence MS, Erglis A, Menown IBA, et al. Percutaneous coronary angioplasty versus coronary artery bypass grafting in treatment of unprotected left main stenosis (NOBLE): a prospective, randomised, open-label, non-inferiority trial. Lancet. 2016;388:2743-52.

6. Bianco V, Kilic A, Mulukutla S, Gleason TG, Kliner D, Aranda-Michel E, et al Outcomes for percutaneous coronary intervention versus coronary artery bypass grafting in patients with reduced ejection fraction. J Thorac Cardiovasc Surg. 2021;161:1022-31.e5.

7. King G, Nielsen R. Why propensity scores should not be used for matching. Polit Anal. 2019;27:435-54.

8. Velazquez EJ, Lee KL, Jones RH, Al-Khalidi HR, Hill JA, Panza JA, et al. Coronary-artery bypass surgery in patients with ischemic cardiomyopathy. $N$ Engl J Med. 2016;374:1511-20.

9. Sun LY, Gaudino M, Chen RJ, Bader Eddeen A, Ruel M. Long-term outcomes in patients with severely reduced left ventricular ejection fraction undergoing percutaneous coronary intervention vs coronary artery bypass grafting. JAMA Cardiol. 2020;5:631.

10. Sharot T. The optimism bias. Curr Biol. 2011;21:R941-5.
See Article page 1022.

\section{Commentary: Coronary \\ revascularization in patients with left ventricular systolic dysfunction}

Stephen J. Huddleston, MD, $\mathrm{PhD}$, and

Rosemary F. Kelly, MD

In this issue of the Journal, Bianco and colleagues ${ }^{1}$ present compelling evidence that coronary artery bypass grafting (CABG) offers improved long-term survival, decreased risk of readmission, increased freedom from combined

\footnotetext{
From the Division of Cardiothoracic Surgery, Department of Surgery, University of Minnesota Medical School, Minneapolis, Minn.

Disclosures: The authors reported no conflicts of interest.

The Journal policy requires editors and reviewers to disclose conflicts of interest and to decline handling or reviewing manuscripts for which they may have a conflict of interest. The editors and reviewers of this article have no conflicts of interest.

Received for publication July 13, 2020; revisions received July 13, 2020; accepted for publication July 14, 2020; available ahead of print July 18, 2020.

Address for reprints: Rosemary F. Kelly, MD, 420 Delaware St SE, MMC 207,

Minneapolis, MN 55455 (E-mail: kelly071@umn.edu).

J Thorac Cardiovasc Surg 2021;161:1033-4

$0022-5223 / \$ 36.00$

Copyright (c) 2020 by The American Association for Thoracic Surgery

https://doi.org/10.1016/j.jtcvs.2020.07.048
}

\section{Check for updates}

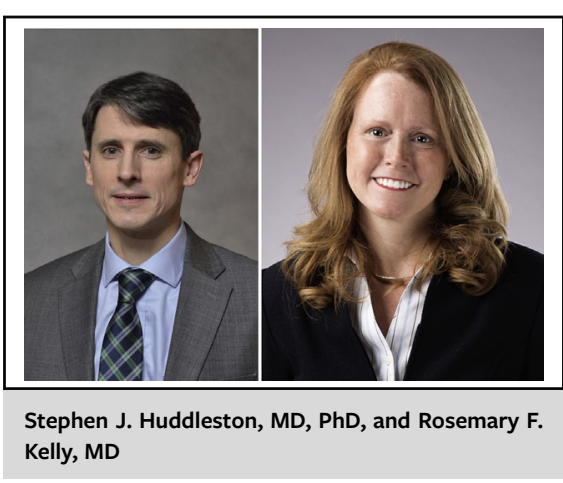

CENTRAL MESSAGE

Use a multidisciplinary approach

to choose between coronary

artery bypass grafting and

percutaneous coronary inter-

vention for coronary artery dis-

ease with reduced left ventricular

ejection fraction.

major adverse cardiac and cerebrovascular events, and decreased need for revascularization when compared with percutaneous coronary intervention (PCI). The authors are 